\title{
Influence of arbuscular mycorrhizal fungi on the nematicidal properties of leaf extracts of Thymus vulgaris $\mathrm{L}$.
}

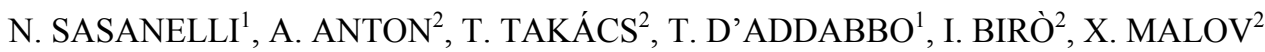

\author{
${ }^{1}$ Institute for Plant Protection - C.N.R., Via G. Amendola 122/D, 70126 Bari, Italy, \\ E-mail: n.sasanelli@ba.ipp.cnr.it; ${ }^{2}$ Research Institute for Soil Science and Agricultural Chemistry - Budapest, \\ Herman O. 15. H-1525 Budapest, Pf 35, Hungary
}

\begin{abstract}
Summary
The effect of arbuscolar mycorrhizal fungi (AMF) on the nematicidal activity of Thymus vulgaris against the rootknot nematodes Meloidogyne incognita and M. javanica was investigated in two in vitro experiments. In the first experiment egg masses of $M$. incognita and $M$. javanica were immersed for 3 weeks in aqueous leaf extracts of thyme plants non-inoculated or previously inoculated with Glomus mosseae or mixed AMF strains (Sclerocystis sinuosa, Glomus claroideum-1, G. claroideum-2 and G. claroideum-3). Thereafter the hatching test continued in distilled water for five more weeks. In the second experiment egg masses of both Meloidogyne species were exposed to the different thyme extracts for 4, 8 and 16 hours and then incubated in distilled water for 8 weeks. Distilled water and $5 \mathrm{mg} / \mathrm{ml}$ aqueous solution of fenamiphos nematicide were used as controls. Numbers of second stage juveniles emerging weekly were expressed as cumulative percentages of the total egg content of the egg masses. In the first experiment juvenile emergence from eggs of both Meloidogyne species immersed in thyme extracts for three weeks was completely suppressed since the first week. Hatching of eggs of $M$. incognita in all the extracts was significantly lower than that in water control, although emergence in the extract from uninoculated thyme plants was significantly higher than the others and no statistical different from that of aqueous fenamiphos solution. Emergence of $M$. javanica juveniles was significantly lower after immersion in all the extracts than in distilled water control and aqueous fenamiphos solution. In the second experiment a 4hour exposure to the extract from thyme inoculated with $G$. mosseae and mixed AMF population significantly reduced the final hatch of $M$. incognita in comparison to distilled water. A 16-hour exposure to the extract from mixed AMF inoculated plants resulted in a significantly lower egg hatch than the shorter exposure times, whereas no statistical difference was found between 4 and 8 hour exposure to both extracts. Emergence of $M$. javanica juveniles was
\end{abstract}

statistically lower than in water only after 16 hours exposure to the extracts from mixed AMF strains inoculated plants, but no difference was found among the different exposure times. Growth of $T$. vulgaris was significantly increased only by the infections of mixed AMF strains.

Keywords: Glomus spp.; Meloidogyne spp.; nematicidal properties; Thymus vulgaris; Sclerocystis sinuosa

\section{Introduction}

Environment and human health concerns require to reduce nematicide use and to develope alternative safer and effective compounds for nematode control (Noling \& Becker, 1994). Plants may represent a source of natural nematicides, as a high number of nematicidal compounds are already reported in many species (Chitwood, 2002).

Active principles from Lamiaceae plants and/or their constituents showed a broad spectrum of activity against insects, mites, plant pathogenic fungi and also nematodes (Isman, 2000).

Investigations focused mainly on the nematicidal properties of essential oils from many lamiaceous species (Oka et al., 2000; Pandey et al., 2000), whereas only few studies regarded the nematicidal activity of crude aqueous extracts or green biomass of these plants (Chatterjee et al., 1982). Nematicidal properties of Thymus spp. was previously investigated on the virus-vector nematode Xiphinema index Thorne et Allen, which was consistently suppressed either by the aqueous extracts and the green biomass of different Thymus species (Insunza et al., 2001a; Aballay et al., 2004). The main active component of Thymus spp. is the phenolic monoterpene thymol, which demonstrated to reduce drastically population of various phytoparasitic nematode species soil either in vitro and in the soil (SolerSerratosa et al., 1996).

Arbuscular mycorrhizal fungi (AMF) are obligatory 
biotrophic symbionts living in the roots of most terrestrial plants (Gerdemann \& Nicolson, 1963; Sieverding, 1991), among which also lamiaceous plants (Mago \& Mukerji, 1994). Positive effects of AMF on plant nutrition and growth are well known (Marschner, 1997; Takács \& Vörös, 2003), as well as other aspects such as biocontrol toward plant pathogens, tolerance to water stress, and adverse environmental conditions, but little is known about the potential of AMF to affect the content of active compounds generated by secondary metabolism pathways. Several studies reported the effect of mychorrizal symbiosis on the content of bioactive plant metabolites like phenols (Zhu \& Yao, 2004), terpenoids (Akiyama \& Hayashi, 2002) and also volatile compounds (Guerrieri et al., 2004), whereas only few reports are available on the influence of mycorrhizal colonization on essential oil content and biocidal properties of lamiaceous species (Copetta et al., 2006) and no specific investigation on thyme.

This paper reports the results of two in vitro assays aimed to verify the potential influence of root colonization by different strains of AMF on thymol content of T. vulgaris plants and, consequently, on the nematicidal activity of aqueous extracts of this lamiaceous plant on the root-knot nematodes $M$. incognita and $M$. javanica.

\section{Materials and Methods}

\section{Plant growth and mycorrhizal parameters}

Two months old thyme seedlings, previously sown in steam sterilized $\left(6 \mathrm{hrs}\right.$ at $\left.100{ }^{\circ} \mathrm{C}\right)$ sandy soil, were transplanted $(2$ plants per pot) in thirty clay pots filled with $4,000 \mathrm{~g}$ sterilised sandy soil (64.4\% sand, $18.5 \%$ silt, $16.8 \%$ clay, $1.1 \% \mathrm{OM})$. Chemical characteristics of the soil were: $\mathrm{pH}_{(\mathrm{H} 2 \mathrm{O})} 8.25, \mathrm{pH}_{(\mathrm{KCl})} 7.55, \mathrm{AL}-\mathrm{P}_{2} \mathrm{O}_{5} 888 \mathrm{mg} \cdot \mathrm{kg}^{-1}, \mathrm{AL}-\mathrm{K}_{2} \mathrm{O}$ 397 mg.kg ${ }^{-1}, \mathrm{KCl}-\mathrm{NH}_{4}-\mathrm{N} 2.91, \mathrm{KCl}^{-N^{3}}-\mathrm{N} 11.6 \mathrm{mg} \mathrm{kg}{ }^{-1}$, humus content $0.9 \%$. After one month, batches of ten pot $\mathrm{s}$ were inoculated with Glomus mosseae (Nicol. \& Gerd.) Gerd. \& Trappe or with a mixed population of AMF strains (Sclerocystis sinuosa (Gerdermann \& Bakshi) Almeida \& Schenck, Glomus claroideum-1, G. claroideum-2 and $G$. claroideum-3 Schenck \& Smith), both at a density of $10 \%$ $\mathrm{w} / \mathrm{w}$ inoculum pot $^{-1}$ ). AMF species were isolated from a calcareous chernozem soil at Nagyhörcsök (Hungary). Ten pots with non-inoculated plants were used as control.

Four months after the AMF inoculation, plants of each group were uprooted and the effect of mycorrhizal infection on plant growth was evaluated recording total plant weight and top dry weight. Mycorrhizal dependency of thyme plants was calculated by expressing the difference between the total plant weight or top dry weight of the mycorrhizal inoculated and the non-inoculated plants as the percentage of the total plant weight or top dry weight of mycorrhized inoculated plants (Plenchette et al., 1983). Root samples collected from each plant were cleaned and stained by Phillips and Hayman's method (1970) and indigenous AMF colonizations were counted on the intact root systems by a stereoscopic dissecting microscope. Frequency of mycorrhizal infection and quantity of arbus- cules on thyme roots were estimated by scoring the density of infection on five $30 \mathrm{~cm}$ root segments by a five class system (Trouvelot et al. 1986).

\section{Experiments}

Thyme extracts were prepared by soaking green leaves from the uprooted plants in distilled water (1:4) for $24 \mathrm{hrs}$. Leaves were then comminuted in a blender $(8,000 \mathrm{rpm})$ and the suspension filtered through Non Waven $\mathrm{N}^{\circ}$ 261/A circular filter paper. Extracts were then stored in plastic bottles and kept in a freezer until used.

Batches of 25 egg masses (averaging 400 eggs per mass) of $M$. incognita (Kofoid et White) Chitw. and M. javanica (Treub) Chitw., previously reared on tomato cv. Roma in glasshouse at $25 \pm 2{ }^{\circ} \mathrm{C}$, were handy picked up from infested roots and placed in $2 \mathrm{~cm}$ diam sieves $(215 \mathrm{~mm}$ aperture). Each sieve was put in a $3.5 \mathrm{~cm}$ diam Petri dish and three $\mathrm{ml}$ of each test solution were added to submerge the egg masses. Dishes were arranged in a complete randomized block design with four replicates per treatment and incubated in a growth cabinet at $20^{\circ} \mathrm{C}$.

In the first experiment the egg masses were removed from the test solutions after three weeks and then the incubation continued in distilled water for five more weeks (Sasanelli \& Di Vito, 1991).

In a second experiment the batches of egg masses were immersed for 4, 8 and 16 hours in the leaf extracts and then transferred to distilled water and incubated as in the first experiment. There were four replications for each treatment.

Distilled water and $5 \mathrm{mg} / \mathrm{ml}$ aqueous solution of fenamiphos (ethyl 4-methylthio-m-tolyl isopropylphosphoramidate) (Greco \& Thomason, 1980) were used as controls in the first experiment and only distilled water in the second. Emerged second stage nematode juveniles were removed and counted at weekly intervals, renewing distilled water at the same time. The hatching test was run for eight weeks.

At the end of both experiments, the egg masses were dissolved by shaking in a $1 \%$ sodium hypochlorite aqueous solution (Hussey \& Barker, 1973) and the unhatched eggs were counted. Numbers of second stage juveniles emerging weekly were expressed as cumulative percentages of the total egg content of the egg masses (hatched + unhatched eggs). Percentage hatches from the second experiment were referred to control $(100 \%)$ in order to allow comparison of data of the two nematode species.

Data from the first experiment were statistically analysed, after transformation in arcsen root square values, by ANOVA and means compared by Least Significant Difference's Test and Student's $t$ Test. In the second experiment the effects of leaf extracts, exposure times and nematode species and their interactions were examined by statistic analysis of variance for a 4 × 3 × 2 factorial design.

Analysis of thymol in thyme leaves and their aqueous extracts

1. Fresh leaves were chopped in small pieces and they were put in HS tubes $(150-200 \mathrm{mg})$ and subjected to GC 
analysis.

2. Leaf aqueous extracts. Chopped leaves of thyme plants were homogenized in a mortal, diluted in distilled water (1:4, fresh weight ratio) and shaken overnight.

Thyme leaves and aqueous extracts were sealed in vials and stored at $-20{ }^{\circ} \mathrm{C}$ until analysis.

Table 1. Extent of the AMF infection (F\%) and arbuscular richness (A\%) in roots of thyme in soil inoculated with Glomus mosseae or a mixture of AMF strains

\begin{tabular}{cccc}
\hline Treatment & $\begin{array}{c}\text { Frequency of the } \\
\text { AMF infection }(\mathrm{F} \%)^{*}\end{array}$ & $\begin{array}{c}\text { Extent of the AMF } \\
\text { arbuscularity (A\%) }\end{array}$ \\
\hline $\begin{array}{c}\text { T vulgaris + G. mosseae } \\
\text { Tvulgaris + Mixed AMF }\end{array}$ & $94.6^{\mathrm{a}} \mathrm{A}^{\mathrm{b}}$ & 31.1 & $\mathrm{~A}$ \\
T vulgaris & $85.3 \mathrm{~A}$ & 11.3 & $\mathrm{~B}$ \\
& $0.0 \mathrm{~B}$ & 0.0 & $\mathrm{C}$ \\
\hline
\end{tabular}

Thymol content was measured by gas chromatography (Perkin Elmer Clarus 500 gas chromatography and Headspace). Quantification was based on multiple headspace extraction (MHE) and total vaporization technique (TVT) with FID detector, eliminating the matrix effects. Thymol content was determined in comparison to Thymol std. (Reanal) and each measure was repeated three times for each sample.

Data from GC analysis were statistically analysed by ANOVA and means compared by Least Significant Difference's Test. in the roots inoculated with $G$. mosseae $(31 \%)$ than in samples from plants infected with mixed inoculum (11\%). Biomass production of mixed AMF inoculated plants was significantly increased by AMF colonization. Total plant weight and top dry weight of mycorrhized thyme plants were $38-113 \%$ and $11-17 \%$ higher than non-inoculated plants (Table 2). No significant difference was observed between the two AMF treatments, whereas plants inoculated with mixed AMF strains resulted significantly heavier than non inoculated control. Mycorrhizal dependency was 28 and $10 \%$ in G. mosseae and 53 and $15 \%$ in mixed AMF strains, respectively, on the base of total plant weight and top dry weight.

In the first experiment, most of the eggs from the egg masses in distilled water hatched within three weeks (Table 3 and 4). Aqueous solution of fenamiphos significantly reduced hatching of both Meloidogyne species compared to distilled water. Emergence of $M$. incognita and $M$. javanica was almost completely suppressed in T. vulgaris leaf extracts from uninoculated plants since the first week, resulting significantly lower than that in water control and fenamiphos solution.

After the third week and until the end of the experiment emergence of juveniles of $M$. incognita in all the extracts was not different from fenamiphos, although emergence in the extract from uninoculated plants was significantly higher than that in the other extracts. Eggs of $M$. incognita previously exposed to fenamiphos solution showed a significantly hatch increase in the last week of the experiment (Table 3).

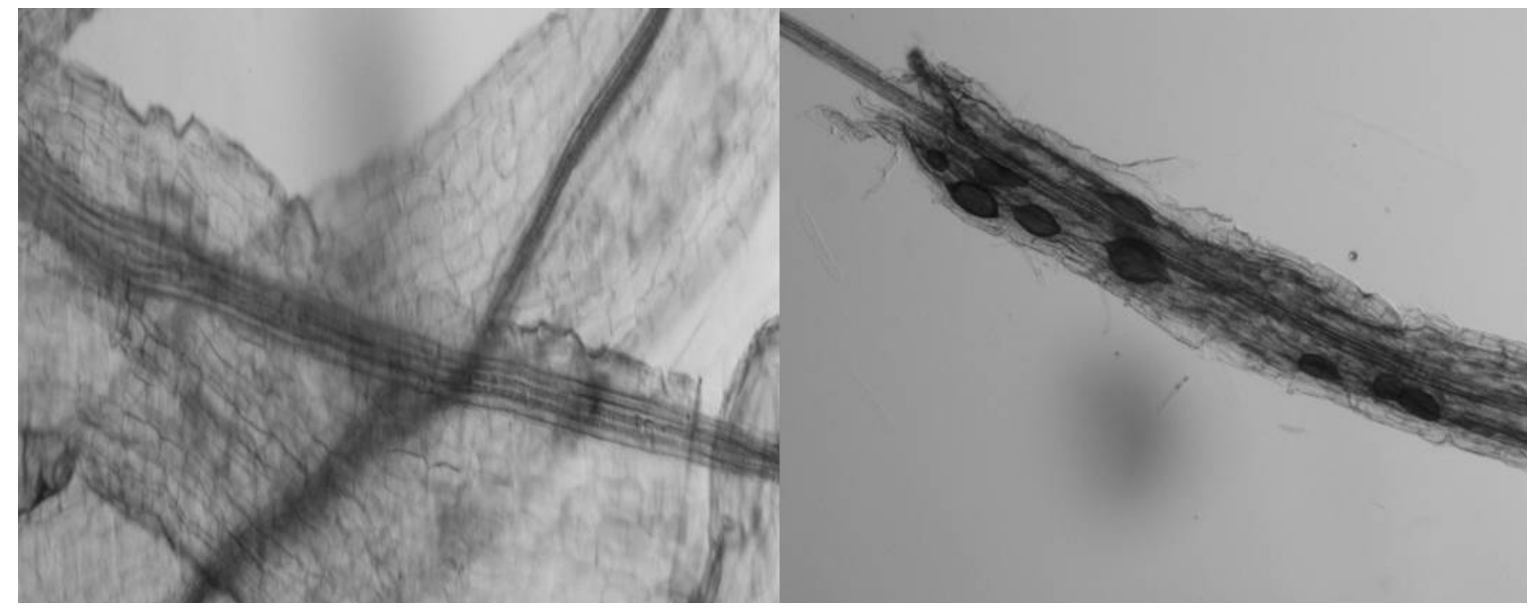

Fig. 1. Segments of thyme roots non inoculated (on the left) and vesicules in Glomus mosseae infected thyme root (on the right)

\section{Results}

Microscopic observation of thyme root samples did not reveal AMF colonization in sterilized soil neither before and after transplanting. A high root colonization was observed in the plants inoculated with $G$. mosseae or mixed AMF strains, as frequencies of infection of 95 and $85 \%$, respectively, were calculated, without significant differences between the two treatments (Table 1; Fig. 1). Extent of the AMF arbuscularity, indicative of the symbiotic efficiency of endomycorrhizal fungi, was significantly higher
Emergence of $M$. javanica juveniles in the extracts from mychorrized thyme plants was suppressed since the first week in comparison with that in water and fenamiphos solution. Egg hatch was always significantly lower in all thyme extracts than in fenamiphos solution, but mortality of eggs exposed to the extracts from $G$. mosseae inoculated plants was significantly higher than that in the other two extracts (Table 4).

Egg hatch of both Meloidogyne species was not furtherly increased after removing egg masses from the thyme extracts, thus suggesting that these extracts were lethal to the 
Table 2. Effect of AMF inoculation on the growth of Thymus vulgaris

\begin{tabular}{ccccccc}
\hline Treatment & $\begin{array}{c}\text { Total plant } \\
\text { weight }(\mathrm{g})\end{array}$ & \% Increase* & $\begin{array}{c}\text { Mycorrhizal } \\
\text { dependency }\end{array}$ & $\begin{array}{c}\text { Top dry } \\
\text { weight }(\mathrm{g})\end{array}$ & $\begin{array}{c}\text { \% } \\
\text { Increase }\end{array}$ & $\begin{array}{c}\text { Mycorrhizal } \\
\text { dependency }\end{array}$ \\
\hline $\begin{array}{c}\text { T.vulgaris }+ \\
\begin{array}{c}\text { G. } \text { mosseae } \\
\text { T.vulgaris }+ \\
\text { Mixed AMF }\end{array}\end{array}$ & $116.7 \mathrm{AB}^{\mathrm{a}}$ & 38 & 28 & $13.6 \mathrm{~A}$ & 11 & 10 \\
$\begin{array}{c}\text { T.vulgaris } \\
\text { I.velg }\end{array}$ & $84.6 \mathrm{~A}$ & 113 & 53 & $14.4 \mathrm{~A}$ & 17 & 15 \\
\hline
\end{tabular}

Mean of five replicates.

${ }^{a}$ Data flanked in each column followed by same letters are not statistically different according to LSD's Test (P=0.01);

* Compared to non-inoculated thyme

eggs. At the end of the experiment for both Meloidogyne species finally cumulative hatching percentage from the egg masses exposed to the all extracts and fenamiphos solution was significantly lower than that of control in distilled water.

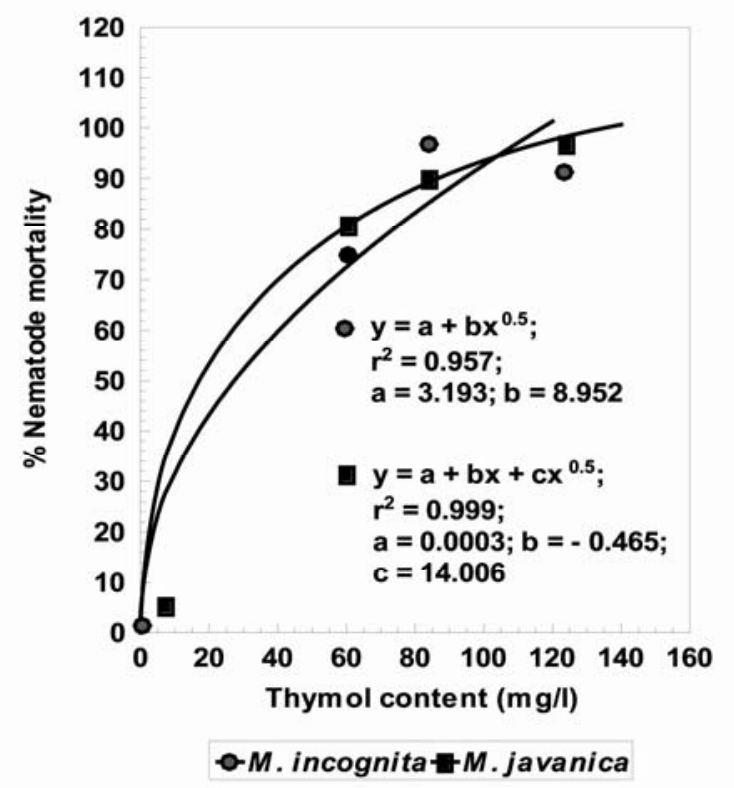

Fig. 2. Relationship between $M$. incognita and $M$. javanica per cent egg mortality $(y)$ and thymol content in leaf aqueous extract (mg/l).

Mortality of $M$. incognita and $M$. javanica eggs exposed to thyme extracts resulted also significantly higher than fenamiphos with the exception for extract from uninoculated plants on $M$. incognita. Moreover, extract from thyme plants inoculated with $G$. mosseae was significantly more effective than those from mixed AMF strains inoculated plants and, for $M$. javanica, also than extract from non inoculated plants.

In the second experiment the final hatch of $M$. incognita, expressed as percentage of the control (100\%), was significantly reduced after 4 hour exposure to the extract from thyme inoculated with $G$. mosseae and mixed AMF population in comparison to distilled water (Table 5). No statistical difference was found between 4 and 8 hour exposure to both extracts, whereas there was a significant decrease after 16 hour exposure to the extract from mixed AMF population inoculated plants compared to the shorter exposure times. The hatch of $M$. incognita in the extract from non-inoculated thyme plants was lower than that in water control after 8 hour immersion of the egg masses. In this extract a significant difference was found only between 4 and 8 hour exposure times.

Juvenile emergence of $M$. javanica in thyme extracts was statistically lower than the water control only after 16 hours exposure to the extracts from mixed AMF strains inoculated plants. No difference was found among the different exposure times.

Factorial analysis of variance showed highly significant main effects for the factors type of extract, exposure time and nematode species. Significant interactions were found between nematode species and the other factors (extracts and exposure time), whereas there was no interaction of extracts with exposure time. Interaction among the three factors resulted significant at $\mathrm{P}=0.01$.

A significant difference was found in thymol content of leaves and aqueous extracts of Thymus vulgaris plants inoculated and uninoculated with AMF (Table 6).

Based on the results of the first experiment nematode egg mortality was positively correlated with leaf thymol content (Fig. 2), as well as a mathematical relationship between nematode egg mortality and exposure time to different extracts was fitted to the experimental data from the second experiment (Table 7). The equations reasonably explain the above relationships, as indicated by the high values of the correlation coefficient $\mathrm{R}^{2}$.

\section{Discussion and Conclusions}

Experiments in vitro evidenciated the strong biocidal effect of thyme extracts on both Meloidogyne species although this effect was evident only after a 16 hour exposures. Nematicidal activity of crude extracts from lamiaceous plants was already reported in previous experiments. Insunza et al. (2001a; 2001b) found that a 24 hours exposure to leaf and flower aqueous extracts of Thymus serpyllum L. was lethal to Xiphinema index and X. americanum $s$. $l$. Chatterjee et al. (1982) reported that exposure of $M$. incognita juveniles to the crude extracts of Ocimum sanctum L. and $O$. basilicum L. resulted in $100 \%$ mortality within 120 and $160 \mathrm{~min}$. 


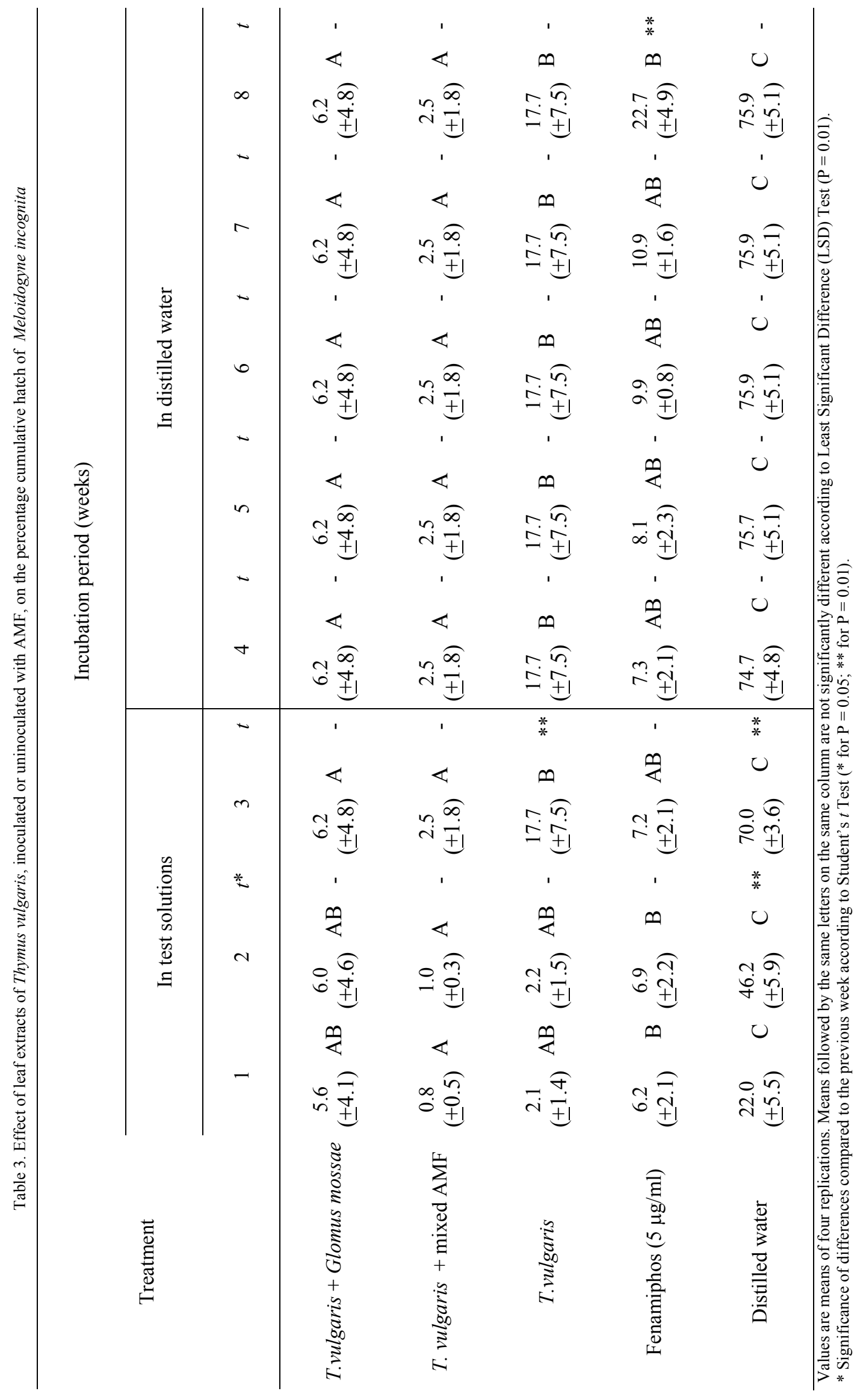




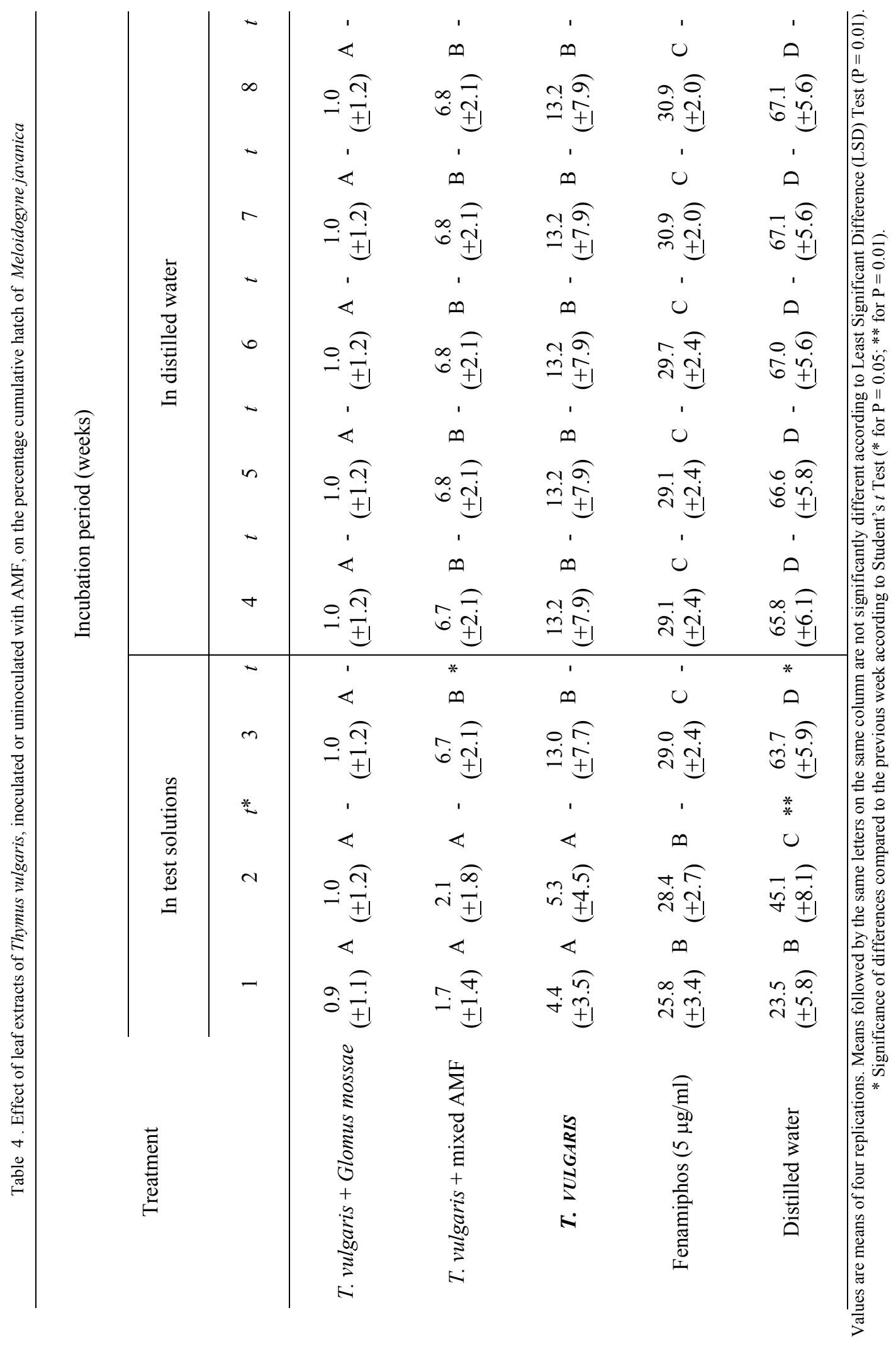




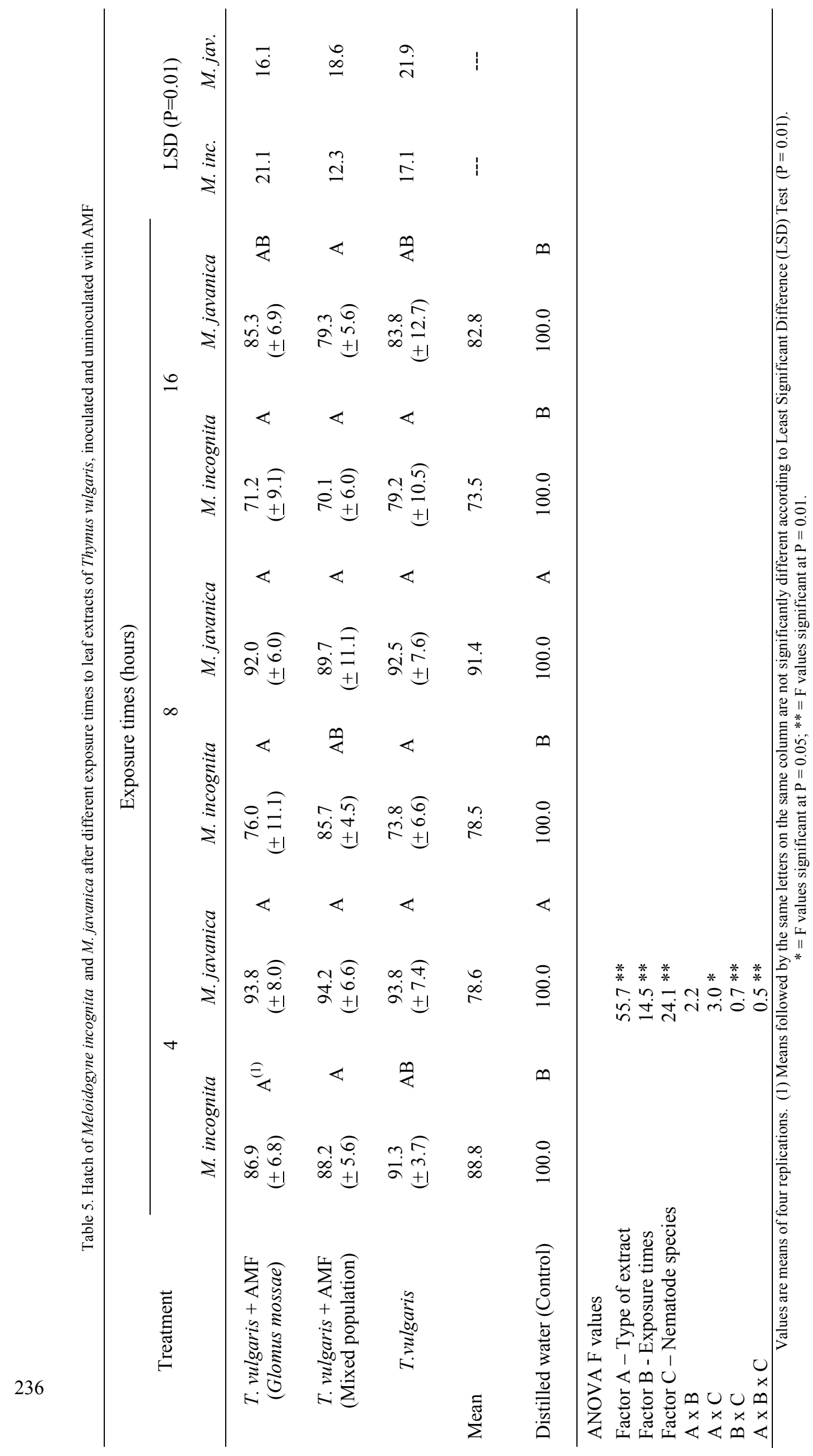


Table 6. Thymol content in leaves and aqueous extracts of Thymus vulgaris plants inoculated and uninoculated with AMF

\begin{tabular}{|c|c|c|c|c|}
\hline \multirow[b]{2}{*}{ Treatment } & \multicolumn{4}{|c|}{ Thymol content } \\
\hline & \multicolumn{2}{|c|}{$\begin{array}{l}\text { In leaf tissues } \\
\text { (mg/Kg f.w.) }\end{array}$} & \multicolumn{2}{|c|}{$\begin{array}{l}\text { In aqueous extract } \\
\qquad(\mathrm{mg} / \mathrm{l})\end{array}$} \\
\hline T. vulgaris + G. mosseae & $1570^{1}$ & $\mathrm{~A}^{2}$ & 126 & A \\
\hline T. vulgaris + Mixed AMF & 1077 & B & 86 & $\mathrm{~B}$ \\
\hline T. vulgaris & 742 & $\mathrm{C}$ & 59 & $\mathrm{C}$ \\
\hline
\end{tabular}

${ }^{1}$ Mean of three replications.

${ }^{2}$ Data flanked in the column followed by same letters are not statistically different according to LSD's Test $(\mathrm{P}=0.01)$

Essential oils in thyme plant tissues and their components may be considered as main responsible of the biocidal activity of this species. Thyme contains a $1-2 \%$ of essential oils, mainly represented by the isomeric monoterpenoids thymol $(30-70 \%)$ and carvacrol $(3-15 \%)$ (Zambonelli et al., 2004; Reddy et al., 1998; Rustaiyan et al., 2000). However, other compounds are present as cymol, terpinene-4-ol, thymol-methyl-ether and caryophyllene (Fig. 3).

Nematicidal properties of thyme essential oil and of thymol and carvacrol are largely demonstrated, as Oka et al. (2000) found that essential oil of T. vulgaris reduced juveniles mobility and egg hatching of $M$. javanica and 250 $\mathrm{ml} / \mathrm{l}$ thymol and carvacrol inhibited egg hatch on the same nematode. At the same concentration, thymol and carvacrol caused $100 \%$ mortality of Caenorhabditis elegans, but were less potent against the root lesion nematode Pratylenchus penetrans (Tsao \& Yu, 2000). A 161 ppm lethal concentration $\left(\mathrm{LC}_{90}\right)$ of thymol in soil was found against $M$. arenaria on soybean (Soler-Serratosa et al., 1996). secticidal properties (Duke et al., 1992; Regnault-Roger et al., 1993).

As a mechanism of interruption of nervous system was found for thymol and carvacrol in insects (Ryan \& Byrne, 1988), a similar mode of action could be supposed for the nematicidal action of thyme (Korayem et al., 1993).

Broad spectrum of action of thyme makes this plant a valuable species for the preparation of environmentally safe biopesticides. In a small pot experiment in soil infested by $M$. javanica thymol $(75 \mathrm{mg} / \mathrm{kg}$ soil) and especially carvacrol reduced formation of galls on tomato roots, whereas in a 31 pot experiment on cucumber $200 \mathrm{mg} / \mathrm{kg}$ soil of essential oils containing carvacrol were more effective than those containing thymol (Oka et al., 2000).

However, possible negative effect of essential oils on soil microrganisms and particularly mychorrizae should be also evaluated. Mycorrhizal colonization by Glomus intraradices Schenck \& Smith on tomato was negatively affected by treatments with $250 \mathrm{ml}$ carvacrol and $250 \mathrm{mg}$ thymol/100 $\mathrm{ml}$ distilled water, whereas infectivity of $G$.

Table 7. Relationship between $M$. incognita and $M$. javanica per cent egg mortality $(y)$ and exposure time $(x)$, in different thyme extracts

\begin{tabular}{lclc}
\hline \multicolumn{1}{c}{ Treatment } & Nematode species & Equation & $\mathrm{R}^{2}$ \\
\hline \multirow{2}{*}{ T. vulgaris + G. mosseae } & M. incognita & $\ln y=3.7814+1.6963 / \mathrm{x}^{0.5}-53.9746^{-\mathrm{x}}$ & 0.99 \\
& M. javanica & $\ln y=1.9521+0.0007 \mathrm{x}^{2.5}-22.3489^{-\mathrm{x}}$ & 0.99 \\
T. vulgaris + Mixed AMF & M. incognita & $\ln y=2.557+0.0002 \mathrm{x}^{3}-15.1476^{-\mathrm{x}}$ & 1.00 \\
& M. javanica & $\ln y=2.1925+0.0008 \mathrm{x}^{2.5}-68.393^{-\mathrm{x}}$ & 0.75 \\
T. vulgaris & M. incognita & $y=0.5059+6.0799 \mathrm{x}^{0.5}$ & 0.99
\end{tabular}

Moreover, thyme essential oil and its main components have been also reported for fungicidal and antibacterial activities (Panizzi et al., 1993; Muller-Ribeau et al., 1995; Janssen et al., 1987; Kurita et al., 1981; Paster et al., 1990; Daferera et al., 2000; 2003), but showed also herbicidal effects (Angelini et al., 2003; Tworkoski, 2002) and in- mosseae was inhibited only by thymol (Calvet et al., 2001).

A possible alternative to liquid formulations could be represented by the use of thyme as green manure. Soil incorporation of the aerial parts of $T$. vulgaris as green manure significantly suppressed population of $X$. index on 

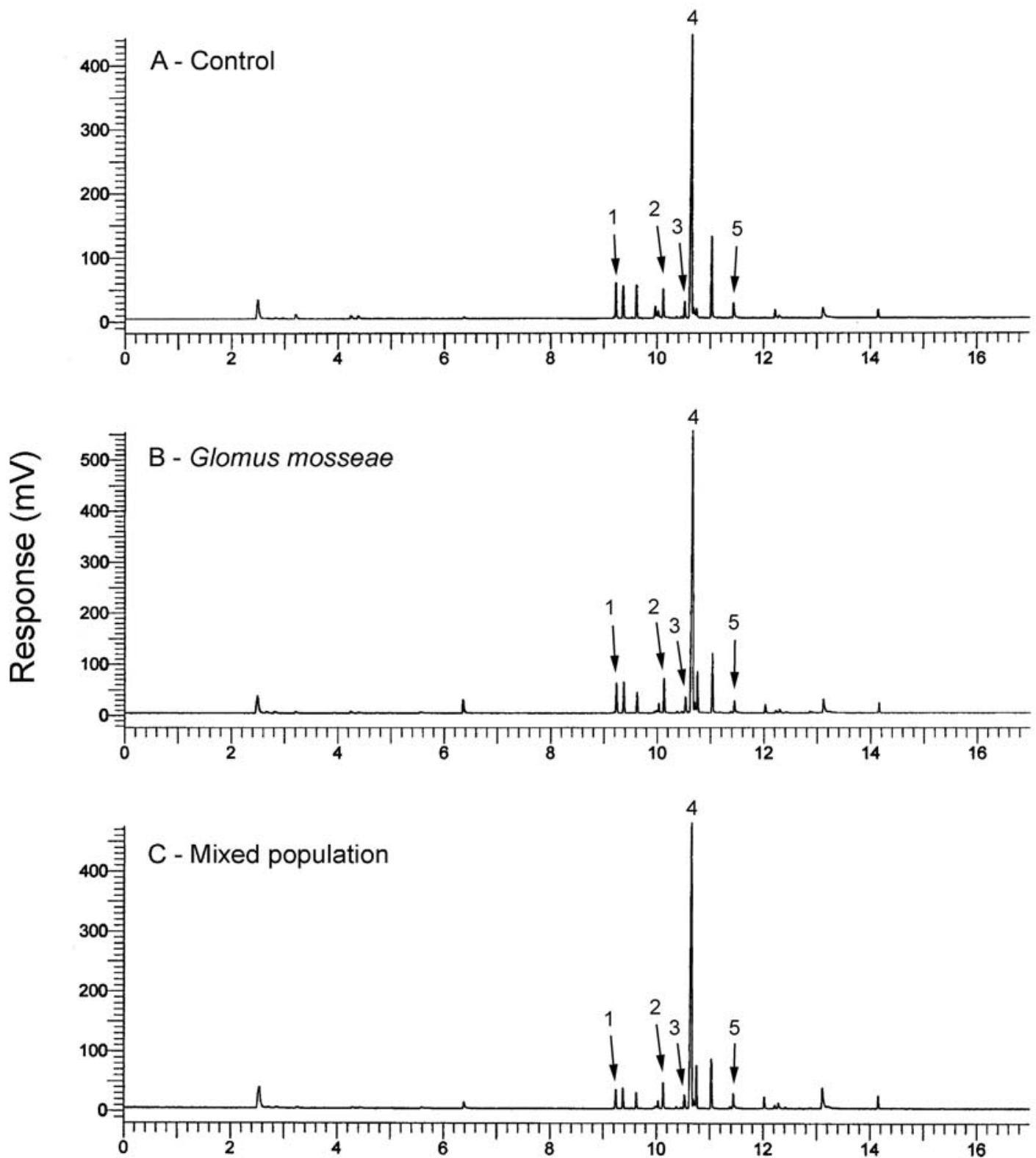

Time (min)

Fig. 3 Chromatogram of the main volatile compounds ( $1=$ cymol; $2=$ terpin-4-ol; $3=$ thymol-methyl-ether; $4=$ thymol; $5=$ caryophillene $)$ in leaves of uninoculated thyme plants (A) or inoculated with Glomus mosseae (B) or mixed population (C).

grapevine when added at $2 \% \mathrm{w} / \mathrm{w}$ in a greenhouse pot experiment (Aballay et al., 2004), but was not suppressive on $X$. index and X. americanum s.l. in field trials (Aballay \& Insunza, 2002; Aballay et al., 2001).

Chemical analyses showed that thymol content was increased by mychorrization of thyme roots. Few reports are available about the effects of AM fungi on the production of essential oils in a limited choice of lamiaceous species. A relation between the presence of AM fungi, increased growth, essential oil accumulation, and improved mineral uptake was reported for Mentha arvensis (Khaliq \& Janardhanan 1997; Gupta et al., 2002; Freitas et al., 2004).
Khaosaad et al. (2006) showed that G. mosseae increases the concentration of essential oils in two genotypes of $O$. vulgare but not in P-fertilized nonmycorrhizal plants. Moreover, in a comparative analysis of the effects induced by three AM fungi, Copetta et al., (2006) found that inoculation with Gigaspora rosea Nicolson \& Schenck BEG 9 increased biomass, root branching and length, and total amount of essential oil in basil $O$. basilicum L. and that increased oil yield was associated to a significantly larger number of peltate glandular trichomes (main sites of essential oil synthesis) in the basal and central leaf zones. Increased growth and development in AM plants, com- 
pared to nonmycorrhizal ones, was reported for many different species (Smith \& Read, 1997). The increase of biomass production observed in AMF infected thyme plants would be useful in the perspective of using these plants as a green manure or producing nematicidal formulations. The results of the present work concerning $T$. vulgaris are in agreement with such reports. However, effects of mychorrization on plant development may be different, depending on the fungal species (Copetta et al., 2006).

Therefore, in conclusion, mychorrized thyme plants soil could be suggested for integrated nematode management strategies, as it provides a good pest suppressivity reducing the impact on soil - plant equilibrium compared to chemical nematicides.

\section{Acknowledgements}

Work was carried out in the framework of the Bilateral Agreement between CNR (National Research Council Italy) and MTA (Hungarian Academy of Sciences - Hungary) 2007-2009.

The Authors contributed equally in conduction of the experiments.

\section{References}

ABALlAY, E., INSUNZA, V. (2002): Evaluation of plants with nematicidal properties in the control Xiphinema index on table grapes cv. Thompson seedless in the central zone of Chile. Agric. Tec., 62: 357 - 365

ABAllay, E., Flores, P., InsunZA, V. (2001): Nematicidal effect of eight plant species on Xiphinema americanum sensu lato in Vitis vinifera, var. Cabernat Sauvignon in Chile. Nematropica, 31: 95 - 102

ABAllay, E., SEPUlvedA, R., InSUNZA, V. (2004): Evaluation of five nematode antagonistic plants used as green manure to control Xiphinema index Thorne et Allen on Vitis vinifera L. Nematropica, 34: 45 - 51

AKIYAMA, K., HAYASHI, H. (2002): Arbuscular mycorrhizal fungus promoted accumulation of two new triterpenoids in cucumber roots. Biosci. Biotechnol. Biochem., 66: 762 - 769. DOI: 10.1271/bbb.66.762

Angelini, L. G., CARPAnESe, G., CiOni, P. L., Morelli, I., Macchia, M., Flamini, G. (2003): Essential Oils from Mediterranean Lamiaceae as Weed Germination Inhibitors. J. Agric. Food Chem., 51(21): 6158 - 6164. DOI: 10.1021/ jf 0210728

Calvet, C., Pinochet, J., Camprubi, A., Estaún, V., RODRÍGUEZ-KABANA, R. (2001): Evaluation of natural chemical compounds against root-lesion and root-knot nematodes and side-effects on the infectivity of arbuscular mycorrhizal fungi. Eur. J. Plant Pathol., 107: 601 - 605. DOI: 10.1023/A:1017954315942

Chatterjee, A., Sukul. N. C., Laskar, S., GHOSHMAJUMDAR, S. (1982): Nematicidal principles from two species of Lamiaceae. J. Nematol., 14: 118 - 120

Chitwood, D. J. (2002): Phytochemical based strategies for nematode control. Annu. Rev. Phytopathol., 40: 221 -
249. DOI: 10.1146/annutev.phyto.40.032602.130045

Copetta, A., LinguA, G., Berta, G. (2006): Effects of three AM fungi on growth, distribution of glandular hairs, and essential oil production in Ocimum basilicum L. Var. Genovese. Mycorrhiza, 16: 485 - 494. DOI: 10.1007/S00 572-006-0065-6

Daferera, D. J., Ziogas, B. N., Polissiou, M. G. (2000): GC-MS analysis of essential oils from some Greek aromatic plants and their fungitoxicity on Penicillium digitatum. J. Agric. Food Chem., 48(6): 2576-2581. DOI: 10.1021/jf990835x

Daferera, D. J., Ziogas, B. N., Polissiou, M. G. (2003): The effectiveness of plant essential oils on the growth of Botrytis cinerea, Fusarium sp. and Clavibacter michiganensis subsp. michiganensis. Crop Prot., 22: 39 - 44. DOI : 10.1016/S0261-2194(02)00095-9

Duke, J. A., James, L. F., Keeler, R. F., Bailey, E. M., Cheeke, P. R., Hegarty, M. P. (1992): Biting the biocide bullet. In: Duke J. A., Keeler R. F., BAIley E. M., Cheeke P. R., Hegarty M. P. (Eds.) Proceedings of the Third International Symposium "Poisonous Plants". Iowa State University Press, Ames, USA, 474 - 478

FreitAs, M. S. M., MARtins, M. A., CURCino VieirA, I. J. (2004): Yield and quality of essential oils of Mentha arvensis in response to inoculation with arbuscular mycorrhizal fungi. Pesqui. Agropecu. Bras., 39: 887 - 894

Gerdemann, J. W., Nicolson, T. H. (1963): Spores of mycorrhizal Endogone species extracted from soil by wet sieving and decanting. Trans. Br. Mycol. Soc. 46: $235-$ 244

GRECO, N., THOMASON, I. J. (1980): Effect of phenamiphos on Heterodera schachtii and Meloidogyne javanica. J. Nematol., 12: 91 - 96

Guerrieri, E., Lingua, G., Digilio, M. C., Massa, N., BERTA, G. (2004): Do interactions between plant roots and the rhizosphere affect parasitoid behaviour? Ecol. Entomol., 29: 753 - 756

Gupta, M. L., Prasad, A., Ram, M., Kumar, S. (2002): Effect of the vesicular-arbuscular mycorrhizal (VAM) fungus Glomus fasciculatum on the essential oil yield related characters and nutrient acquisition in the crops of different cultivars of menthol mint (Mentha arvensis) under field conditions. Bioresour. Technol., 81: $77-79$. DOI: 10.1016/S0960-8524(01)00109-2

HusSEY, R. S., BARKER, K. R. (1973): A comparison of methods of collecting inocula of Meloidogyne spp. including a new technique. Plant Dis. Rep., 57, 1025 - 1028 InsunZA, V., ABAllay, E. MACAYA, J. (2001a): Nematicidal activity of aqueous plant extracts on Xiphinema index. Nematol. Mediterr., 29: 35 - 40

InSUNZA, V., ABAllay, E., MACAYA, J. (2001b): In vitro nematicidal activity of aqueous plant extracts on clilean populations of Xiphinema americanum sensu lato. Nematropica, 31: $47-54$

ISMAN, M. B. (2000): Plant essential oils for pest and disease management. Crop Protection, 19: 603 - 608. DOI: 10.1016/S0261-2194(00)00079-x

Janssen, A. M., Sheffer, J. J. C., BAerheim Svendsen, 
A. (1987): Antimicrobial activity of essential oils: A 19761986 literature review: aspects of the test methods. Planta Med., 53: 395 - 398

KHALIQ, A., JANARDHANAN, K. K. (1997): Influence of vesicular arbuscular mycorrhizal fungi on the productivity of cultivated mints. J. Med. Arom. Plant Sci., 19: 7 - 10 KhaosaAd, T., Vierheilig, H., Nell, M., ZitTerlEglSeER, K., NovaK, J. (2006): Arbuscular mycorrhiza alters the concentration of essential oils in oregano (Origanum sp., Lamiaceae). Mycorrhiza, 16(6), 443 - 446. DOI: 10.1007/S00572-006-0062-9

Korayem, A. M., Hasabo, S. A, Ameen, H. H. (1993): Effects and mode of action of some plant extracts on certain plant parasitic nematodes. Anz. Schaedl.-Kde. Pfl.Schutz Umweltschutz, 66(2): 32 - 36

Kurita, N., Miyaji, M., Kurane, R., TAKahara, Y. (1981): Antifungal activity of components of essential oils. Agric. Biol. Chem., 45: 945 - 952

MAGO, P., MukerJi, K. G. (1994): Vesicular arbuscular mycorrhizae in Lamiaceae: I. Seasonal variation in some members. Phytomorphology 44(1 - 2): $83-88$

MARSCHNER, H. (1997): The Soil-Root Interface (Rhizosphere) in Relation to Mineral Nutrition. In: MARSCHNER, H. (Ed.) Mineral nutrition of higher plants. Academic Press, London, pp. $537-594$

Müller-Riebau, F., Berger, B., Yegen, O. (1995): Chemical composition and fungitoxic properties to phytopathogenic fungi of essential oils of selected aromatic plants growing wild in Turkey. J. Agric. Food Chem., 43: $2262-2266$

Noling, J. W., Becker, J. O. (1994): The challenge of research and extension to define and implement alternatives to methyl bromide. 1994. J. Nematol., 26: 573 - 586 OKA, Y., NACAR, S., PUTIEVSKY, E., RAVID, U., YANIV, Z., SPIEGEL, Y. (2000): Nematicidal activity of essential oils and their components against the root-knot nematode. Phytopathology, 90: 710 - 715. DOI: 10.1094/PHYTO.20 00.90.7.710

PAndey, R., Kalra, A., TAndon, S., Mehrotra, N., SingH, H. N., KUMAR, S. (2000): Essential oils as potent sources of nematicidal compounds. J. Phytopathology, 148: 501-502. DOI: 10.1046/j.1439-0434.2000.00493.x PANizZI, L., Flamini, G., CiONI, P., L., MORELli, I. (1993): Composition and antimicrobial properties of essential oils of four Mediterranean Lamiaceae. J. Ethnopharmacol., 39(3): $167-170$

Paster, N., Juven, B. J., ShaAya, E., Menasherov, M., Nitzan, R., WeIsSlowicz, H., RAVID, U. (1990): Inhibitory effect of oregano and thyme essential oils on moulds and foodborne bacteria. Lett. Appl. Microbiol., 11: 33 - 37 PHILlIPS, J. M., HAYMAN, D. S. (1970): Improved procedures for clearing roots and staining parasitic and VAM fungi for rapid assessment of infection. Trans. Brit. Mycol. Soc., 55, $158-161$

Plenchette, C., Fortin, J. A., Furlan, V. (1983): Growth responses of several plant species to mycorrhizae

RECEIVED JULy 8, 2009 in a soil of moderate P-fertility. I. Mycorrhizal dependency under field conditions. Plant Soil, 70, $199-209$

Reddy, M. V. B., Angers, P., Gosselin, A., Arul, J. (1998): Characterization and use of essential oil from Thymus vulgaris against Botrytis cinerea and Rhizopus stolonifer in strawberry fruits. Phytochemistry, 47: $1515-$ 1520. DOI: 10.1016/S0031-9422(97)00795-4

Regnault-Roger, C., Hamraoul, A., Holeman, M., THERON, E., PINEL, R. (1993): Insecticidal effect of essential oils from Mediterranean plants upon Acanthoscelides obtectus Say (Coleoptera, Bruchidae), a pest of kidney bean (Phaseolus vulgaris L.). J. Chem. Ecol. (USA), 19(6): $1233-1244$

Rustaiyan, A., Masoudi, S., Moufared, A., Kamalinejad, M, LajeVardi, T., Sedaghat, S., YARI, M. (2000): Volatile constituents of three Thymus species grown wild in Iran. Planta Med., 66: 197 - 198

RYAN, M.F., BYRNE, O. (1988): Plant-insect coevolution and inhibition of aceylcholinesterase. J. Chem. Ecol., 14: $1965-1975$

Sasanelli, N., Di Vito, M. (1991): The effect of Tagetes spp. on the hatching of an Italian population of Globodera rostochiensis. Nematol. mediterr., 19: 135 - 137

SiEVERDING, E. (1991): Vesicular-Arbuscular Mycorrhiza Management in Tropical Agrosystems. Eschborn, pp. $52-$ 54

SMITH, S.E., READ, D.J. (1997): Mycorrhizal symbiosis, 2nd edn. Academic Press, London

Soler-Serratosa, N., KoKalis-Burelle, N., RodriGuez-Kabana, R., Weaver, C.F., King, P.S. (1996): Allelochemicals for control of plant-parasitic nematodes. 1. In vivo nematicidal efficacy of thymol and thymol/ benzaldeyde combinations. Nematropica, 26: 57 - 71

TAKÁCS, T., VÖRÖS, I. (2003): Role of the arbuscular mycorrhizal fungi in the water and nutrient supply of their host plant. (In Hungarian) Növénytermelés. 52, 583 - 593 Trouvelot, A., Kough, J. L., Gianinazzi-Pearson, V. (1986): Mesure du Taux de mycorrhization VA d'un systeme radiculaire. In ler Symposium Europeen sur les Mycorrhizes. INRA, Paris, pp. 217 - 221

TSAO, R., YU, O. (2000): Nematicidal activity of monoterpenoid compounds against economically important nematodes in agriculture. J. Essential Oil Res., 12: 350 - 354

TWORKOSKI, T. (2002): Herbicide effects of essential oils. Weed Sci., 50: 425 - 431

ZAmbonelli, A., D'Aulerio, A. Z., SeVeri, A., Benvenuti, S., MAgGi, L. Bianchi, A. (2004): Chemical composition and fungicidal activity of commercial essential oils of Thymus vulgaris L. J. Essential Oil Res., 16: 69 $-74$

ZHU, H. H., YAO, Q. (2004): Localized and systematic increase of phenols in tomato roots induced by Glomus versiforme inhibits Ralstonia solanacearum. J. Phytopathol. 152: 537 - 542. DOI: 10.1111/j.1439-0434.2004. 00892.x

ACCEPTED SEPTEMBER 3, 2009 